\title{
Renoprotective effect of red grape (Vitis vinifera L.) juice and dark raisins against hypercholesterolaemia-induced tubular renal affection in albino rats
}

\author{
S. Ali ${ }^{1}$, A. Alahmadi², R. Hamdy ${ }^{1}$, E.A. Huwait ${ }^{2}$, A. Alansari ${ }^{3}$, N. Ayuob¹, 4 \\ ${ }^{1}$ Anatomy Department, Faculty of Medicine, King Abdulaziz University, Saudi Arabia \\ ${ }^{2}$ Biology Department, Faculty of Science, King Abdulaziz University, Saudi Arabia \\ ${ }^{3}$ Home Science Education Department, Faculty of Education, Umm al-Qura University, Makkah, Saudi Arabia \\ ${ }^{4}$ Medical Histology Department, Faculty of Medicine, Mansoura University, Egypt
}

[Received: 2 April 2018; Accepted: 27 May 2018]

Background: Red grape juice (RGJ) and dark raisins (DR) are rich in polyphenols and antioxidants. This study aimed to assess the efficacy of $R G J$ and $D R$ in protecting the renal tubules against hypercholesteraemic-induced pathological changes. Materials and methods: Forty albino rats divided into four groups $(n=10)$ were utilised in this study. They included the control, high cholesterol diet (HCD)-fed, $H C D+R G J$-fed, and HCD $+D R$-fed groups. Body weight gain, food and water intake, blood and insulin levels, lipid profile and kidney functions were assessed at the start of the experiment and after 12 weeks. The right kidney was dissected out and processed for both light and electron microscopic examination. Desmin and cytokeratin antibodies were utilised as histologic markers to assess the integrity of the proximal (PTS) and distal tubules (DTS) of the kidney.

Results: Administration of HCD resulted in hypercholesterolaemia in rats as evidenced by the lipid profile. The PTs of hypercholesteraemic rats appeared dilated with hyaline casts and mitochondria in most of the tubular cells were affected. Immunohistochemical assessment revealed affection of both PTs and DTs. Both RGJ and $D R$, when administered along with the HCD for 12 weeks, improved the lipid profile, kidney functions as well as the histologic and cellular changes-induced by hypercholesterolaemia in the rats. The effect of raisins was superior to $R G J$ which might be due to its high contents of fibres and proteins.

Conclusions: This study highlighted the importance of supplementation of red grape and raisins in protection against the harmful effects induced by deposition of fat on the renal tubules' structure and function. (Folia Morphol 2019; 78, 1: 91-100)

Key words: kidney, grapes, raisins, hypercholesterolaemia, function, structure

\section{INTRODUCTION}

Hypercholesterolaemia became the most frequently encountered medical problem worldwide. Among its causes are the bad dietary habits and increased dependence on fast food [9]. Hypercholesterolaemia was reported to be linked to liver disease [42], cardiovascular diseases [28] and brain stroke [26]. Dyslipidaemia could be induced in an

Address for correspondence: Dr. N. Ayoub, Department of Histology, Faculty of Medicine, Mansoura University, Egypt, tel: 00201066513745 , e-mail: nasraayuob@gmail.com, nasraayoub@man.edu.eg 
animal model when fed high fat diet [20]. This facilitates the study of the effect of this metabolic disorder on the structure and function of different body organs and the test of the efficacy of new drugs and natural product in treating or preventing such condition.

Although a lot of medications that lower the circulating cholesterol levels are available in the market, unfortunately, they are mostly associated with many side effects [6]. The concept of the consumption of functional foods or dietary supplements to lower serum cholesterol was introduced by Kwok et al. [25].

Antioxidants from natural sources were found to have both prophylactic and protective effects against hypercholesterolaemia-induced organ affections [7]. Red grape (RG) (Vitis vinifera $L$.) is rich in flavonoids, polyphenols, anthocyanins, resveratrol and other stilbene derivatives; trans-resveratrol and trans-piceatannol [14]. Those substances were reported to possess potent antioxidant effect [18]. In both fresh and dried form, the RG provides a good source for natural antioxidants [35]. It was reported that sun-dried raisins retain the minerals and most of the phytochemicals and antioxidants of the grape, including its resveratrol. In fact, sun-drying enhances the antioxidant content of raisins. Because of the dehydration process, phytonutrients are more concentrated in raisins than in grapes [4].

Although the renal functional and structural alterations in obesity were described in many studies $[24,39]$, few detected studies investigated the effect of high cholesterol diet on the kidney function and structure $[3,21]$. In previous studies, the effect of hypercholesterolaemia on the structure of the renal glomerulus was specifically assessed $[1,5]$. While injury of the glomeruli may precede tubular injury, it is the latter that sets into motion the irreversible process of tubulointerstitial fibrosis, thus leading to loss of kidney structure and function [31]. Therefore, this study aimed to describe the effect of the high-cholesterol diet (HCD) on the structure of the renal tubules and on the renal function in an animal model of hypercholesterolemia and to assess the possible protective effect of RG and black resins in alleviating these effects.

\section{MATERIALS AND METHODS}

Diet and chemicals

The HCD utilised in this study consisted of the rat chow supplemented with $4 \%$ cholesterol powder and
Table 1. Chemical analysis of red grape (RG) and dark raisins (DR)

\begin{tabular}{lcc}
\hline Element [g/100 g] & Amount in RG & DR \\
\hline Phenol compounds & 9.4 & 6.33 \\
Flavones & 0.042 & 0.019 \\
Anthocyanin & 0.34 & 0.002 \\
Vitamin C & 0.0006 & 0.003 \\
Vitamin E & 0.17 & 0.09 \\
Vitamin B1 & 0.09 & 1.099 \\
Vitamin B2 & 0.053 & 1.79 \\
Vitamin B3 & 0.28 & 4.91 \\
Potassium & 0.15 & 0.73 \\
Phosphorus & 0.06 & 0.071 \\
Magnesium & 0.002 & 0.012 \\
Calcium & 0.01 & 0.04 \\
Iron & 0.0002 & 0.002 \\
Protein & 0.46 & 2.4 \\
Carbohydrates & 28.4 & 75.08 \\
Cholesterol & 0 & 0.092 \\
Monounsaturated fatty acids & 0.05 & 1.58 \\
Polyunsaturated fatty acids & 0.03 & 0 \\
Fibbers & 0.96 & 5.9 \\
Moist & 80.5 & 4.92 \\
\hline & & \\
\hline
\end{tabular}

$1 \%$ cholic acid and was obtained from Sigma (Aldrich, St. Louis, Mo, USA). The dose of the cholesterol was calculated according to Thriuchenduran et al. [41].

The dark RG was obtained from the local Jeddah markets (imported from Sheli). It was thoroughly washed with distilled water. The RG juice (RGJ) was prepared using a sterile blender and stored at $4^{\circ} \mathrm{C}$ till the time of use. The RGJ was supplied in the dose described by Castilla et al. [11].

The dark raisins (DR) were purchased from wellknown nut stores in Jeddah (Yemen source). They were thoroughly washed and homogenised using a sterile blender with a small amount of water then packed into small blocks of $1 \mathrm{~g}$ each, and stored in the refrigerator until the time of use. The dose given to the animals was determined based on the method described by Spiller et al. [38].

One hundred grams of both RGJ and DR was assessed in the Analytical Chemistry Unit at Assuit University, Egypt, using mass spectrometry as described by Folin-Ciocalteu procedure [45] in order to determine the composition of them. The components of each were shown in Table 1. 


\section{Animals}

Forty adult male Wister rats were obtained from the animal unit at King Fahd Medical Research Centre (KFMRC), Jeddah, Saudi Arabia. The average weight of the rats was 250-300 g. They were kept for 1 week under the laboratory conditions for acclimatisation (12/12 light-dark cycle, standard temperature $25^{\circ} \mathrm{C}$ and humidity $55 \%$ ). The guidelines of dealing with the experimental animals in research approved in the KFMRC were followed in this study that was also approved by the biomedical research ethics committee, King Abdulaziz University, Jeddah, Saudi Arabia.

The rats were divided into four groups $(n=10)$. The rats of the control group (GI) were allowed to have free access to standard rat pellets and water add libitum. The experimental group (GII) were fed HCD for 12 weeks according to Thriuchenduran et al. [41] while the groups GIII and GIV were fed HCD plus RGJ or DR through gastric gavage respectively for 12 weeks. Body weight, food and water intake were recoded for all rats at the beginning and at the end of experiments.

\section{Biochemical assessment}

At the beginning and at the end of the experiment, rats were anesthetised by light ether and blood samples were cautiously taken from the retro-orbital vein [40]. Serum was separated from these samples at $3000 \mathrm{rpm}$ for $10 \mathrm{~min}$ and stored at $-80^{\circ} \mathrm{C}$ for assessment of the lipid profile and kidney functions.

\section{Histopathological assessment}

After 12 weeks all rats were sacrificed by cervical dislocation under deep ether anaesthesia. The abdomen and chest were opened. Initial perfusion of the heart was done using normal saline followed by $10 \%$ neutral buffered formalin to ensure good fixation. Kidneys were dissected out and weighed. The right kidney was cut in sagittal plane via convex border into 2 halves. One half of the kidney was refixed in 10\% neutral buffered formalin and further processed for routine histological examination using the light microscope (LM). Four-micron-thick paraffin sections were obtained and stained by haematoxylin and eosin [15]. Another set of the paraffin sections were immunohistochemically stained using the standard procedure previously described [5]. Anti-desmin antibody (Dako, Trappes, France) and anti-cytokeratin (CK) antibody (Dako Ltd., Glostrup, Denmark) were used at the dilution 1/100 as described by Petrica et al. [33] to assess the integrity of PTs and distal tubules (DTs), respectively.

Small pieces $\left(1 \mathrm{~mm}^{2}\right)$ were taken from the cortex of the other half of the kidney and fixed in $2.5 \%$ glutaraldehyde in sodium cacodylate buffer and processed for obtaining epoxy resins capsules according to Johannessen [22]. These capsules were sectioned at 0.5-1 $\mathrm{mm}$, stained with toluidine blue and examined by the LM to detect the orientation of the ultrathin sectioning at 500-800 $\AA$. These sections were stained with uranyl acetate and lead citrate, examined and photographed using the electron microscope (EM) (Joel, $100 \mathrm{CXII}$ ) operated at $80 \mathrm{KV}$ at the EM unit, Assuit University, Egypt.

\section{RESULTS}

\section{Chemical analysis of RGJ and DR}

It was observed that both RGJ and DR contained phenolic compounds, flavones and anthocyanin compounds which are well known antioxidants compounds. The latter were present in the RGJ at higher concentrations. Both contained considerable amount of vitamins, but DR contained much more amount of vitamin B complex. The minerals, proteins and fibres were much more abundant in DR than RGJ (Table 1).

\section{Body and kidney weights}

A significant increase in body weight gain was observed in rats fed HCD compared to the control. On the other hand, there was a significant decrease in the weight gain of rats receiving $H C D$ along with either RGJ or DR. The kidney index was decreased in HCD-fed rats compared to the control (Table 2).

\section{Biochemical assessment}

As shown in Table 3, feeding on HCD resulted in a significant increase in blood glucose $(p=0.0002)$, insulin $(p<0.001)$, cholesterol $(p<0.001)$, triglycerides ( $p<0.001)$ and low-density lipoprotein cholesterol ( $p<0.0001$ ) levels, while high-density lipoprotein cholesterol (HDL-C) levels significantly ( $p<0.001)$ decreased compared with those at the start of the experiment (data not shown). Administration of both RGJ and DR significantly improved the lipid profile apart from the HDL-C, reduced the blood glucose and increased the insulin level, with no significant difference between RGJ and DR. Regarding the kidney functions, it was found that creatinine, blood urea 
Table 2. Body weight, water and food intake of the studied groups

\begin{tabular}{|c|c|c|c|c|c|c|}
\hline \multirow[t]{2}{*}{ Parameter } & \multicolumn{2}{|c|}{ Body weight [g] } & \multirow{2}{*}{$\begin{array}{c}\text { Body weight } \\
\text { gain [\%] }\end{array}$} & \multirow{2}{*}{$\begin{array}{c}\text { Water intake } \\
{[\mathrm{mL} / \mathrm{d}]}\end{array}$} & \multirow{2}{*}{$\begin{array}{l}\text { Food intake } \\
{[\mathrm{g} / \mathrm{d}]}\end{array}$} & \multirow{2}{*}{$\begin{array}{c}\text { Kidney index } \\
{[\%]^{*}}\end{array}$} \\
\hline & At the start & At the end & & & & \\
\hline Control (G1) & $240.6 \pm 14.4$ & $376 \pm 14.9$ & $56.9 \pm 11.4$ & $31.5 \pm 1.5$ & $22.5 \pm 1.5$ & $0.68 \pm 0.05$ \\
\hline Hypercholesterolaemia & $231.0 \pm 18.9$ & $418.6 \pm 32.5^{\mathrm{a}, \mathrm{e}}$ & $81.8 \pm 1.8^{\mathrm{a}}$ & $27.1 \pm 2.3$ & $20.1 \pm 1.6^{\mathrm{a}}$ & $0.56 \pm 0.01^{\mathrm{a}}$ \\
\hline Hypercholesterolaemia+RGJ & $261.6 \pm 20.1$ & $391.1 \pm 50.5^{b, e}$ & $49.8 \pm 19.7^{b}$ & $31.0 \pm 2.4$ & $15.1 \pm 1.4^{b}$ & $0.63 \pm 0.08^{b}$ \\
\hline Hypercholesterolaemia+DR & $256.6 \pm 12.1$ & $361.8 \pm 38.0^{c, e}$ & $40.9 \pm 11.4^{c}$ & $28.3 \pm 0.6$ & $30.9 \pm 1.0^{c, d}$ & $0.72 \pm 0.07^{c, d}$ \\
\hline
\end{tabular}

a'Significance of HCD vs. control; ' Significance of $H C D+R G J$ vs. HCD; 'Significance of HCD+DR vs. HCD; dSignificance of HCD+DR vs. HCD+RGJ; eWeight at the start vs. weight at the end. Significance was considered at $\mathrm{p}<0.05$. *Kidney index $\%=$ weight of the kidney $\times 100 /$ body weight; DR — dark raisins; HCD - high cholesterol diet; RGJ - red grape juice

Table 3. Blood glucose, insulin level and lipid profile and kidney functions of the studied group at the end of the experiment

\begin{tabular}{|c|c|c|c|c|c|c|c|c|c|}
\hline Parameter & $\begin{array}{c}\text { Blood } \\
\text { glucose level } \\
{[\mathrm{mg} / 100 \mathrm{~mL}]}\end{array}$ & $\begin{array}{c}\text { Insulin level } \\
{[\mathrm{ng} / \mathrm{mL}]}\end{array}$ & $\begin{array}{c}\text { Cholesterol } \\
{[\mathrm{mmol} / \mathrm{L}]}\end{array}$ & $\begin{array}{c}\text { Triglycerides } \\
\text { [mmol/L] }\end{array}$ & $\begin{array}{c}\text { HDL } \\
\text { cholesterol } \\
{[\mathrm{mmol} / \mathrm{L}]}\end{array}$ & $\begin{array}{c}\text { LDL } \\
\text { cholesterol } \\
{[\mathrm{mmol} / \mathrm{L}]}\end{array}$ & $\begin{array}{l}\text { Creatinine } \\
{[\text { [mmol/L] }}\end{array}$ & $\begin{array}{c}\text { BUN } \\
{[\mathrm{mmol} / \mathrm{L}]}\end{array}$ & $\begin{array}{c}\text { Urea } \\
{[\mathrm{mmo} / \mathrm{L}]}\end{array}$ \\
\hline Control & $100.2 \pm 23.3$ & $0.854 \pm 0.24$ & $50.63 \pm 8.5$ & $47.4 \pm 16.4$ & $24.45 \pm 1.5$ & $35.43 \pm 3$ & $36.1 \pm 9.02$ & $4.5 \pm 1.2$ & $5.68 \pm 1.4$ \\
\hline \multirow[t]{2}{*}{$\mathrm{HCD}$} & $139.9 \pm 13.2$ & $1.765 \pm 0.35$ & $108.81 \pm 10.6$ & $81.12 \pm 19.7$ & $18.42 \pm 2.1$ & $86.59 \pm 1.2$ & $51.7 \pm 10.8$ & $6.7 \pm 1.26$ & $8.5 \pm 2.4$ \\
\hline & $p=0.0002$ & $p<0.001$ & $p<0.001$ & $p<0.001$ & $p<0.001$ & $p<0.001$ & $p=0.0018$ & $p=0.13$ & $p=0.005$ \\
\hline \multirow[t]{2}{*}{$\mathrm{HCD}+\mathrm{RGJ}$} & $102.6 \pm 15.2$ & $0.751 \pm 0.11$ & $63.12 \pm 14$ & $49.7 \pm 16$ & $26.81 \pm 1.5$ & $39.13 \pm 1.3$ & $43.68 \pm 5.75$ & $5.97 \pm 0.23$ & $7.8 \pm 1.3$ \\
\hline & $\mathrm{p} 1=0.001$ & $\mathrm{p} 1<0.001$ & $\mathrm{p} 1<0.001$ & $\mathrm{p} 1<0.001$ & $\mathrm{p} 1=0.098$ & $p<0.001$ & $\mathrm{p} 1=0.04$ & $\mathrm{p} 1=0.02$ & $\mathrm{p} 1=0.7$ \\
\hline \multirow[t]{3}{*}{$\mathrm{HCD}+\mathrm{DR}$} & $100.5 \pm 12.2$ & $0.77 \pm 0.21$ & $57.78 \pm 10.6$ & $42.77 \pm 16$ & $28.11 \pm 1.8$ & $37.2 \pm 5.2$ & $44.2 \pm 3.13$ & $5.4 \pm 1.3$ & $7.3 \pm 2.3$ \\
\hline & $\mathrm{p} 2<0.001$ & $\mathrm{p} 2<0.001$ & $\mathrm{p} 2<0.001$ & $\mathrm{p} 2<0.001$ & $\mathrm{p} 2<0.001$ & $\mathrm{p} 2<0.001$ & $\mathrm{p} 2=0.04$ & $\mathrm{p} 2=0.03$ & $\mathrm{p} 2=0.6$ \\
\hline & p3 $=0.073$ & $\mathrm{p} 3=0.81$ & $\mathrm{p} 3=0.34$ & $\mathrm{p} 3=0.34$ & p3 $=0.09$ & $\mathrm{p} 3=0.27$ & $\mathrm{p} 3=0.71$ & p3 $=0.24$ & $\mathrm{p} 3=0.54$ \\
\hline
\end{tabular}

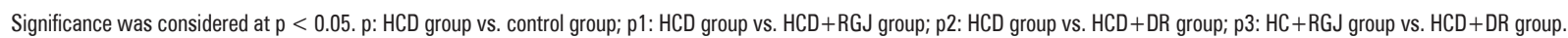
BUN — blood urea nitrogen; DR — dark raisins; HCD — high cholesterol diet; HDL — high density lipoprotein; LDL — low density lipoprotein; RGJ — red grape juice

nitrogen and urea levels were significantly decreased in HCD-fed rats along with RGJ or DR.

\section{Histopathological assessment}

Light microscopy. Proximal tubules (PTs) represent important part of the nephron, the structural unit of the kidney, as most of the urinary filtrate is reabsorbed at this level. On routine histopathological examination, the PTs and the DTs of the control group appeared intact. The PTs of HCD-fed rats appeared dilated with acidophilic casts in their lumina. The cells lining the PTs appeared shorter and some of the peritubular capillaries were dilated and congested. Although some of the renal tubules in the groups treated with RGJ and DR appeared affected, most of the other tubules appeared intact and some peritubular capillaries were congested (Fig. 1). Numerous large lipid droplets existed at the basal parts of tubular cells and within the lumen. Some apoptotic cells were also observed in the renal tubules of HCD-fed rats (Fig. 2).

In order to assess the integrity of the renal tubules, and PTs in particular, the renal cortex was immuno- histochemically stained with anti-desmin antibody. A strong desmin immunoexpression was observed in the PTs of the control rats while those of the HCD-fed rats showed marked decrease in expression. On the other hand, most of the renal tubules of HCD-fed rats along with RGJ or DR had strong desmin expression (Fig. 2). When it came to the integrity of the DCTs, anti-cytokeratin antibody was used to assess it. Most of the renal tubules, the DCTs in particular, of the control rats as well as RGJ- and DR-treated rats showed moderate cytokeratin expression while those of HCDfed rats showed week expression (Fig. 2).

Electron microscopy. Examination of the ultrastructure of the renal tubules showed that feeding the rats with HCD resulted in marked deposition of lipid droplets as well as increased number of lysosomes in the cells of both PTs and DCTs. Cells of the PTs showed smaller and darker mitochondria compared with those of the control rats. Some cells lining the DCTs appeared markedly affected with thickened basement membrane and swollen mitochondria (Figs. 3, 4). Tubular cells of the rats received HCD along with RGJ or 

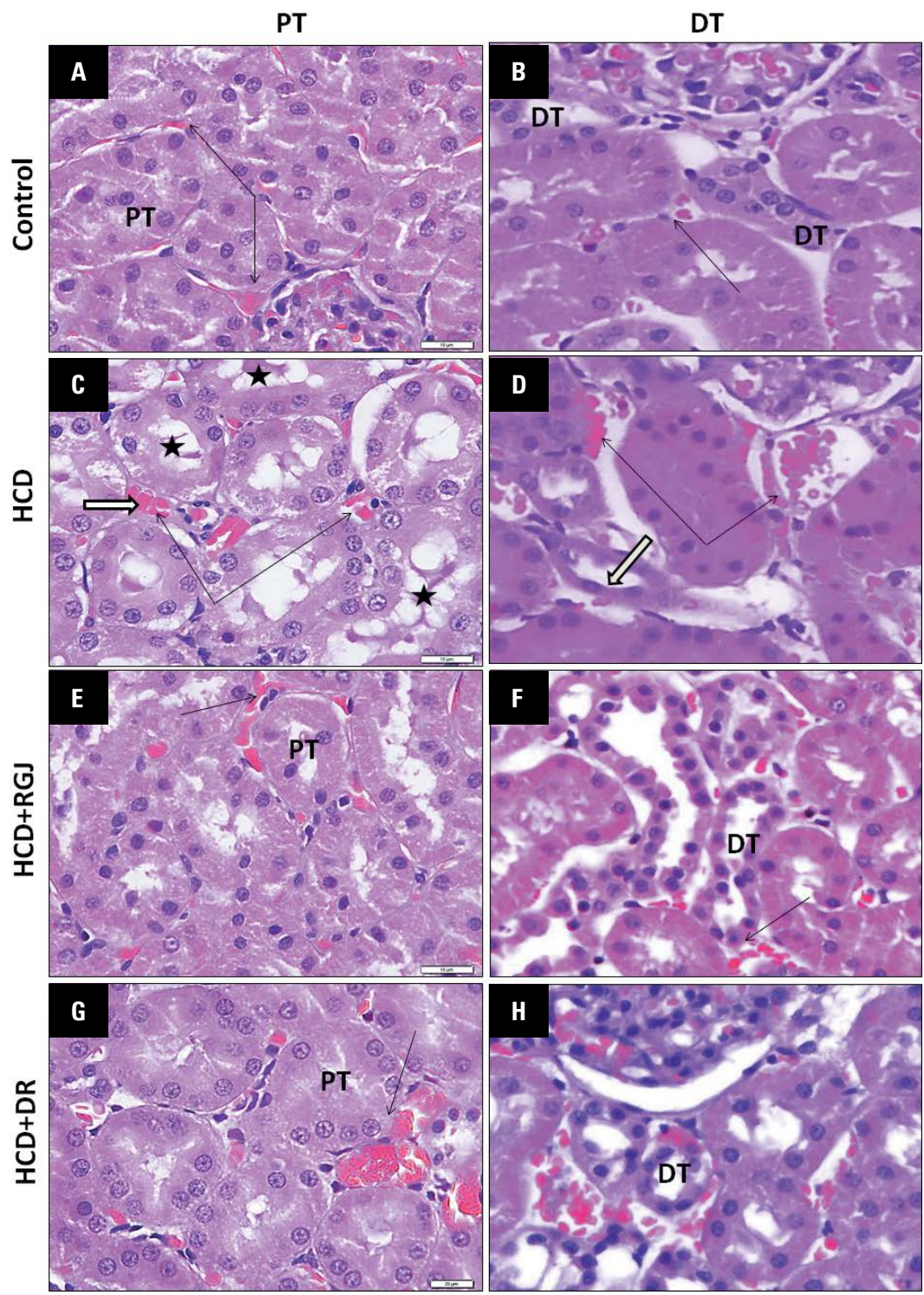

Figure 1. Sections in renal cortex of rat from the control group (A, B) showing intact proximal tubules (PTs) and distal tubules (DTs) with intact peritubular capillaries while those of the rats fed high cholesterol diet (HCD) (C, D) appear congested and dilated. The PTs of these rats appear dilated with hyaline casts (asterisk) in their lumina and the DTs are lined with cells which have dark cytoplasm and dark nuclei (thick white arrow). Renal tubules of the rats received HCD + red grape juice (RGJ) (E, F) or HCD + dark raisins (DR) (G, H) showing same changes but at lesser extent (haematoxylin and eosin, $\times 600$ ).

DR contained no or few lipid droplets and numerous lysosomes and most of the mitochondria appeared intact (Figs. 3, 4).

\section{DISCUSSION}

Hypercholesterolaemia represents a common clinical problem as its complications involve many vital organs like the kidneys [29]. Animal models of hypercholesterolaemia are considered valid tools to study cholesterol homeostasis and test drugs and natural products directed to control disorders in lipid or cholesterol metabolism [32]. This study aimed to assess the impact of HCD-induced hypercholestero- laemia on the structure of the rat renal tubules, in particular, as well as renal functions and to assess the possible protective effect of RG and DR in alleviating these effects. In the present study, feeding rats on diet containing $4 \%$ cholesterol and $1 \%$ cholic acid resulted in marked disturbance of the lipid profile parameters which was reflected in rats' body weight, kidney function and structure. Similar results regarding success of such model were reported by many investigators [23, 32].

Proximal tubules are the first parts of renal tubules where most of the filtered substances are reabsorbed back to blood. Damage of such tubules will result in 


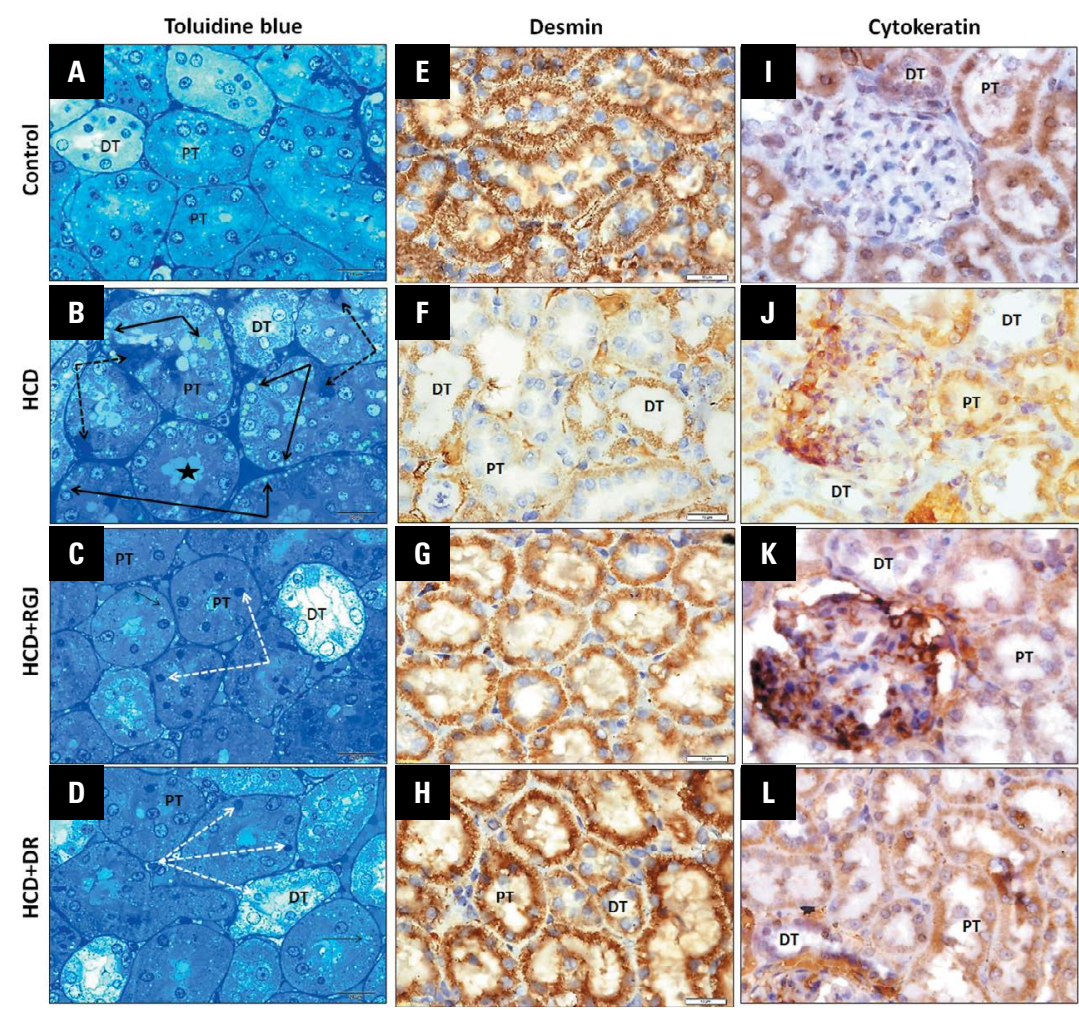

Figure 2. Semithin section of the renal cortex of control rat (A) showing intact proximal tubules (PTs) and distal tubules (DTs) while those of the rat fed with high cholesterol diet (HCD) (B) showing numerous large lipid droplets (thin arrows) at the basal parts of tubular cells (black arrows) and within the lumen (asterisk). Notice the presence of dark apoptotic cells (dotted arrows) in some tubules. Most of the renal tubules in the cortex of rats treated with red grape juice (RGJ) (C) and dark raisins (DR) (E) appear intact apart from few cells with dark nuclei (white dotted arrows) (Toluidine blue, $\times 1000$ ). Renal cortex stained immunohistochemically with desmin showing strong expression in renal tubules of control rats (E) while those of HCD-fed rats (F) show marked decrease specifically in the PTs of rats treated with RGJ (G) and DR (H) showing preservation of desmin expression (Desmin, $\times 600$ ). Renal cortex stained immunohistochemically with cytokeratin showing moderate expression in renal tubules of control rats (I) while those of HCD-fed rats (J) show week expression specifically in the DTs. Most of the renal tubules of rats treated with RGJ (K) and DR (L) showing moderate expression of cytokeratin apart from few DTs (Cytokeratin, $\times 600)$.

loss of the valuable reabsorbed nutrients and electrolytes needed for the organism welfare [12]. In the present study, it was observed that hypercholesterolemia resulting from feeding rats on HCD affected the structure of renal tubules observed by both LM and EM. Among the observed changes was the dilation of the PTs and presence of acidophilic protein casts. These tubular casts were mostly attributed to the hypercholesterolaemia-induced glomerular lesions previously described by Abdel-Hamid [1] and Ayuob [5]. Zoja et al. [46] reported that damaged filtration barrier caused loss of proteins and its appearance within the lumina of the tubules.

Desmin, a cytoskeleton protein, is expressed by various types of cells (epithelial cells, mesangium, tubules, postmitotic myofibroblasts). Desmin expression is affected by certain circumstances, such as hypertension, heavy proteinuria [30]. Petrica et al. [33] reported that desmin stains normal proximal tubular cells and is considered a sensitive marker that detected focal tubular necrosis in early stages of tubular impairment while cytokeratin is expressed in distal and collecting tubular cells and is considered a sensitive marker for focal tubular necrosis. Therefore they were utilised in this study as specific histologic marker of tubular necrosis. It was found that renal tubules, the PTs in particular, of the HCD-fed rats showed marked decrease in desmin expression compared to the control rats. Most of the renal tubules, the DCTs in particular, of HCD-fed rats showed week expression compared with those of the control rats. These findings indicated a negative impact of hypercholesterolaemia on the integrity renal tubular cells.

Accumulation of lipid droplets in the tubular cells, evident in the present study by both LM and EM, could affect the cellular metabolism and induce oxidative stress and lipid peroxidation. The latter induced damage of membranous structures including brush 

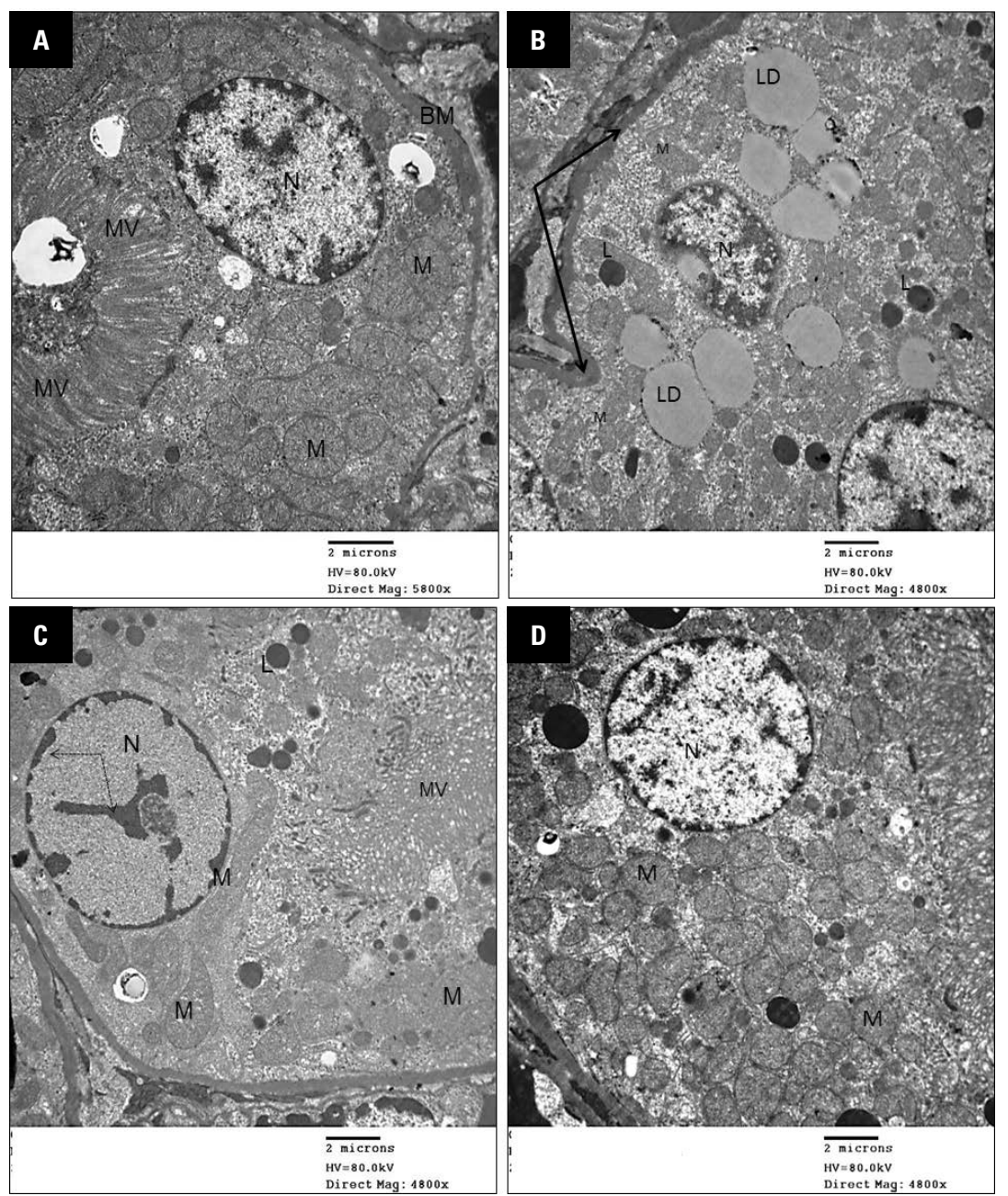

Figure 3. Electron microscope picture of a part of the proximal tubule (PT) of control rat (A) showing intact basement membrane (BM) microvilli (MV), mitochondria (M) and a euchromatic nucleus (N) of the cell. Cells of the PT of high cholesterol diet (HCD)-fed animal have numerous lipid droplets (LD) that appear compressing the nucleus and the mitochondria appear smaller and show dense matrix. Many lysosomes (L) appear in the cytoplasm. Cells of the PT of red grape juice (RGJ)-treated rat (C) and dark resins (DR)-treated rat (D) showing absence of LD and numerous lysosomes. Mitochondria appear of larger size in RGJ-treated rat (C) and of increased number in DR-treated rat (D).

borders of the tubular cells as well as the mitochondria with subsequent impairment in renal function [8]. In a more recent study, Emma et al. [16] reported that lipid accumulation could result in lipotoxicity as fatty acids act as detergents that weaken the membranous structures and enhance cell apoptosis. Mitochondrial changes, indicating its damage, were among the changes observed in hypercholesterolaemic rats in this study. These mitochondrial changes affected the Na-K pump-mediated reabsorption process in the PTs which is dependent on the adenosine triphosphate generated by the mitochondria and cause dysfunction of the tubules [16]. Damaged mitochondria also resulted in release of cytochrome $C$ that set into motion apoptosis, as well as proinflammatory mediators that signal tissue damage [44]. This is an explanation of the ultrastructural signs of cellular damage evident by EM in the renal tubules in this study. Tubular epithelial cells, especially those of PTs have been proved to play a dynamic role in the pathogenesis of tubulointerstitial fibrosis. Among the main mechanisms that contribute to tubular cell activation is activation by glomerular-derived cytokines that reach tubular cells via the urine space, vasa recta or diffusion through interstitial space. Other suggested mechanisms are injury by plasma proteins filtered in excess as a consequence of injury to the glomerular filtration barrier; ischaemia downstream to glomerular injury and hyperfunction of remnant tubules [13, 19].

Natural products rich in antioxidants can be used as safe medicinal products for the early management of many diseases including hyperlipidae- 


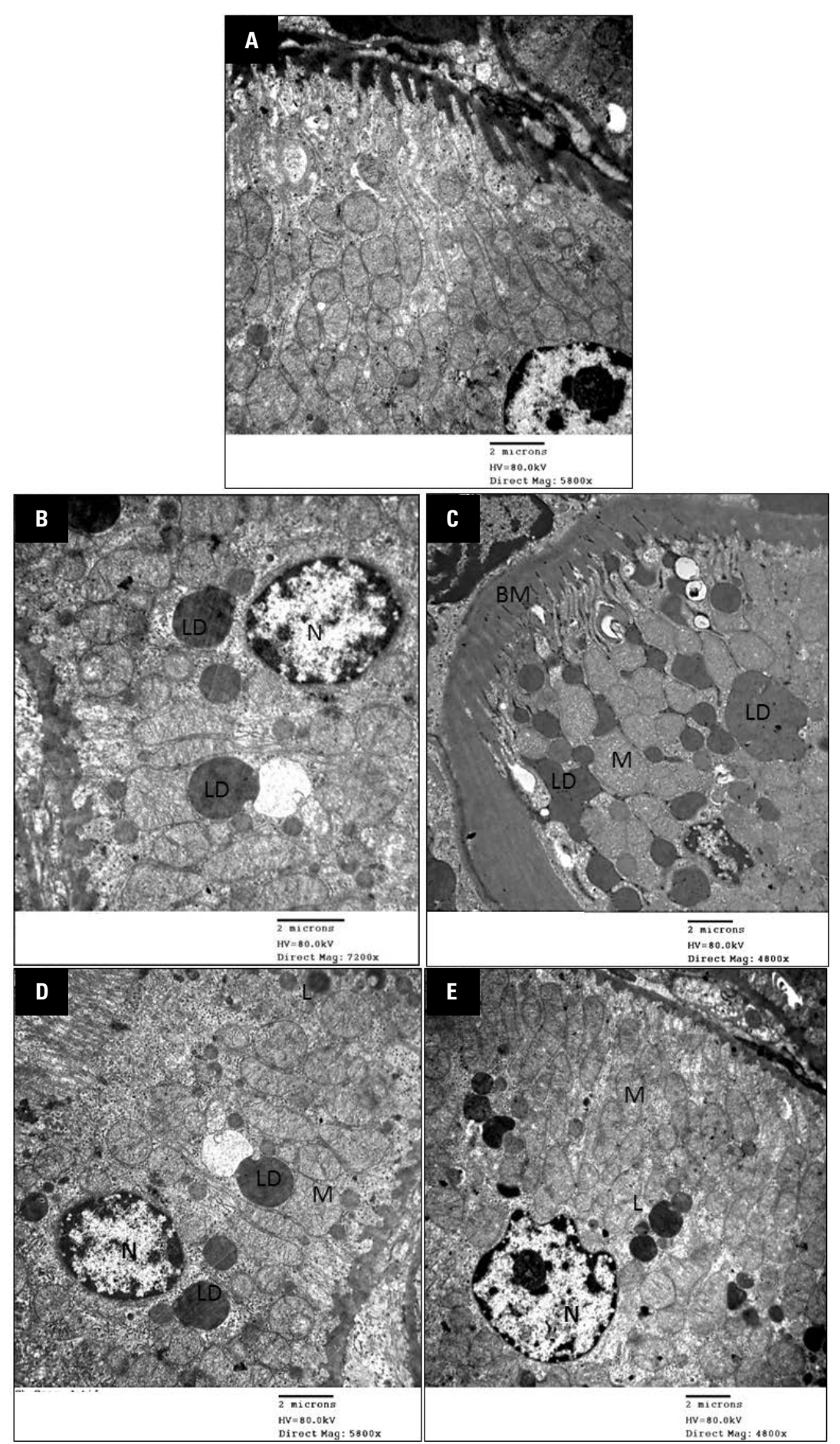

Figure 4. Electron microscope picture of a part of the distal tubule (DT) of control rat (A) showing intact basement membrane (BM) basal infoldings with mitochondria (M) in-between and a euchromatic nucleus (N) of the cell. Cells of the dark resins (DT) of high cholesterol diet (HCD)-fed rat either appear intact (B) with few lipid droplets (LD) or markedly affected (C) with thickened BM numerous large LD, swollen mitochondria (M) and small dark nucleus (N). Cells of the DT of red grape juice (RGJ)-treated rat (D) and DR-treated rat (E) showing few LD and numerous lysosomes (L) and most of the mitochondria (M) appear intact.

mia [27]. Grape was reported to be an important source of healthy nutrients with many health benefits so can be used as supplementation supporting health and protect against oxidative stress-in- duced disorders [37]. In addition, Bagchi et al. [6] proved the efficacy of raisins as excellent source of polyphenols, powerful protective antioxidants against oxidative damage. 
Analysis of fresh RGJ and dried raisins used in this experiment showed that they were rich in many antioxidant compounds such as phenolic compounds, flavones and anthocyanin besides considerable amounts of vitamins and minerals. The presence of high fibre content in raisins made it superior to grape juice in controlling lipid profile possibly by increasing cholesterol absorption from intestine [43]. Present study seems to support such notation.

In the present study, administration of both RGJ and DR improved the lipid profile, the elevated blood glucose level and the disturbed kidney function induced by the HCD. Some previous studies revealed contradicting findings regarding the renoprotective effect of red grape or its products. Pinheiro et al. [34] found that grape seed extract caused an increase in serum urea in rats received methotrexate. In addition, Safa et al. [36] reported that RG seed extract failed to improve gentamicin-induced acute kidney injury. These results may point to a possible interaction between those drugs and RG products. On the other hand, RG consumption and its products were reported to increase serum antioxidant capacity and provide protection against many lesions induced by hyperlipidaemic status. Almajwal and Elsadek [2] found that RG seeds added as $20 \%$ to basal diet showed a significant decrease in the lipid profile, with a significant increase in HDL-C. The authors attributed this effect to grape components such as procyanidins, proanthocyanidins and polyphenols. The latter were also reported by Feng et al. [17], to be powerful free radical scavengers. Bladé et al. [10] added that the hypolipidaemic effects of proanthocyanidins are attributed to their ability to decrease lipid absorption and chylomicron synthesis by the intestine beside very low density lipoprotein secretion by the hepatocytes. This could explain the observed improvement in the histopathological alterations in the renal tubules after administration of RGJ or DR, which we named it "renoprotective effect".

\section{CONCLUSIONS}

In summary, this study raised the importance of supplementation of red grape and raisins in protection against the harmful effects induced by deposition of fat in the renal tubules with subsequent negative impact of the renal functions. Therefore, this study supports the renoprotective effect of red grape and raisins against the high fat diet-induced nephrotoxicity.

\section{Acknowledgements}

The authors thank Yousef Abdullatif Jameel, Chair of Prophetic Medical Applications (YAJCPMA), Faculty of Medicine, King Abdulaziz University, Jeddah, Saudi Arabia, for his support to this study.

\section{REFERENCES}

1. Abdel-Hamid GA. Effect of red grape juice on renal glomeruli in hypercholestremic rats. Life Science J. 2014; 11(6): 234-245.

2. Almajwal AM. Elsadek MF. Lipid-lowering and hepatoprotective effects of Vitis vinifera dried seeds on paracetamol-induced hepatotoxicity in rats. Nutrition Res Pract. 2015; 9(1): 37-42.

3. Altunkaynak ME, Ozbek E, Altunkaynak BZ, et al. The effects of high-fat diet on the renal structure and morphometric parametric of kidneys in rats. J Anat. 2008; 212(6): 845-852, doi: 10.1111/j.1469-7580.2008.00902.x, indexed in $\mathrm{Pu}-$ bmed: 18510511.

4. Anderson JW, Waters AR. Raisin consumption by humans: effects on glycemia and insulinemia and cardiovascular risk factors. J Food Sci. 2013; 78 Suppl 1: A11-A17, doi: 10.1111/1750-3841.12071, indexed in Pubmed: 23789931.

5. Ayuob N. Can raisins ameliorate hypercholesterolemia-induced nephropathy? What is the evidence? Egypt J Histol. 2014; 37(4): 677-688, doi: 10.1097/01. ehx.0000455076.29699.52.

6. Bagchi D, Bagchi M, Stohs Sj, et al. Cellular protection with proanthocyanidins derived from grape seeds. Ann N Y Acad Sci. 2002; 957: 260-270, indexed in Pubmed: 12074978.

7. Baghdadi H. Antioxidant potential of quercetin: remarkable protection against hypercholesterolemia in rats. $\mathrm{Br}$ J Med Med Res. 2014; 4(26): 4382-4391, doi: 10.9734/ bjmmr/2014/11126.

8. Balarini CM, Oliveira MZt, Pereira TMc, et al. Hypercholesterolemia promotes early renal dysfunction in apolipoprotein E-deficient mice. Lipids Health Dis. 2011; 10: 220, doi: 10.1186/1476-511X-10-220, indexed in Pubmed: 22117541.

9. Bipasha M, Goon S. Fast food preferences and food habits among students of private universities in Bangladesh. South East Asia Journal of Public Health. 2014; 3(1): 61-64, doi: 10.3329/seajph.v3i1.17713.

10. Bladé C, Arola L, Salvadó MJ. Hypolipidemic effects of proanthocyanidins and their underlying biochemical and molecular mechanisms. Mol Nutr Food Res. 2010; 54(1): 37-59, doi: 10.1002/mnfr.200900476, indexed in Pubmed: 19960459.

11. Castilla $P$, Echarri $R$, Dávalos $A D$, et al. Concentrated red grape juice exerts antioxidant, hypolipidemic, and antiinflammatory effects in both hemodialysis patients and healthy subjects. Am J Clin Nutr. 2006; 84: 252-62.

12. Curthoys NP, Moe OW. Proximal tubule function and response to acidosis. Clin J Am Soc Nephrol. 2014; 9(9): 1627-1638, doi: 10.2215/CJN.10391012, indexed in Pubmed: 23908456.

13. D'Amico G. Tubulo-interstitial damage in glomerular diseases: its role in the progression of the renal damage. Nephrol Dial Transplant. 1998; 13 Suppl 1: 80-85, indexed in Pubmed: 9507504.

14. Doshi P, Adsule P, Banerjee K, et al. Phenolic compounds, antioxidant activity and insulinotropic effect of extracts prepared from grape (Vitis vinifera L) byproducts. J Food Sci Technol. 2015; 52(1): 181-190, doi: 10.1007/s13197013-0991-1, indexed in Pubmed: 25593367. 
15. Drury RAB. and Wallington EA. Carleton histological technique. Oxford. New York. Toronto. Oxford University Press. 1980.

16. Emma $F$, Montini $G$, Parikh $S$, et al. Mitochondrial dysfunction in inherited renal disease and acute kidney injury. Nature Reviews Nephrology. 2016; 12(5): 267-280, doi: 10.1038/nrneph.2015.214.

17. Feng R, Lu Y, Bowman LL, et al. Inhibition of activator protein-1, NF-kappaB, and MAPKs and induction of phase 2 detoxifying enzyme activity by chlorogenic acid. J Biol Chem. 2005; 280(30): 27888-27895, doi: 10.1074/jbc. M503347200, indexed in Pubmed: 15944151.

18. González-Centeno MR, Jourdes M, Femenia A, et al. Proanthocyanidin composition and antioxidant potential of the stem winemaking byproducts from 10 different grape varieties (Vitis vinifera L.). J Agric Food Chem. 2012; 60(48): 11850-11858, doi: 10.1021/jf303047k, indexed in Pubmed: 23101762.

19. Healy E, Brady HR. Role of tubule epithelial cells in the pathogenesis of tubulointerstitial fibrosis induced by glomerular disease. Curr Opin Nephrol Hypertens. 1998; 7(5): 525-530, indexed in Pubmed: 9818199.

20. Innis SM. Dietary lipids in early development: relevance to obesity, immune and inflammatory disorders. Curr Opin Endocrinol Diabetes Obes. 2007; 14(5): 359-364, doi: 10.1097/MED.0b013e3282be90b9, indexed in Pubmed: 17940463.

21. Jiang $T$, Wang $Z$, Proctor $G$, et al. Diet-induced obesity in C57BL/6J mice causes increased renal lipid accumulation and glomerulosclerosis via a sterol regulatory element-binding protein-1c-dependent pathway. J Biol Chem. 2005; 280(37): 32317-32325, doi: 10.1074/jbc.M500801200, indexed in Pubmed: 16046411.

22. Johannessen J. Instruction and techniques in electron microscopy in human medicine. Mchqraw-Hill Int., Book Co 1978.

23. Joles JA, Kunter U, Janssen U, et al. Early mechanisms of renal injury in hypercholesterolemic or hypertriglyceridemic rats. J Am Soc Nephrol. 2000; 11(4): 669-683, indexed in Pubmed: 10752526.

24. Kang JS, Lee WK, Lee CW, et al. Improvement of high-fat diet-induced obesity by a mixture of red grape extract, soy isoflavone and L-carnitine: implications in cardiovascular and non-alcoholic fatty liver diseases. Food Chem Toxicol. 2011; 49(9): 2453-2458.

25. Kwok CY, Wong CY, Yau MC, et al. Consumption of dried fruit of Crataegus pinnatifida (hawthorn) suppresses high-cholesterol diet-induced hypercholesterolemia in rats. J Funct Foods. 2010; 2(3): 179-186, doi: 10.1016/j.jff.2010.04.006.

26. Lee J, Hong J, Lee K, et al. Endovascular therapy of cerebral arterial occlusions: intracranial atherosclerosis versus embolism. J Stroke Cerebrovasc Dis. 2015; 24(9): 2074-2080, doi: 10.1016/j.jstrokecerebrovasdis.2015.05.003.

27. Li S, Chen G, Zhang C, et al. Research progress of natural antioxidants in foods for the treatment of diseases. Food Sci Hum Well. 2014; 3(3-4): 110-116, doi: 10.1016/j. fshw.2014.11.002.

28. Mazza A, Lenti S, Schiavon L, et al. Nutraceuticals for serum lipid and blood pressure control in hypertensive and hypercholesterolemic subjects at low cardiovascular risk. Adv Ther. 2015; 32(7): 680-690, doi: 10.1007/s12325-0150229-x, indexed in Pubmed: 26202829.

29. Mount P, Davies M, Choy SW, et al. Obesity-Related chronic kidney disease-the role of lipid metabolism. Metabolites. 2015; 5(4): 720-732, doi: 10.3390/metabo5040720, indexed in Pubmed: 26690487.

30. Muchaneta-Kubara EC, el Nahas AM. Myofibroblast phenotypes expression in experimental renal scarring. Nephrol Dial Transplant. 1997; 12(5): 904-915, indexed in Pubmed: 9175042.

31. Ong A, Fine L. Tubular-Derived growth factors and cytokines in the pathogenesis of tubulointerstitial fibrosis: implications for human renal disease progression. Am J Kidney Dis. 1994; 23(2): 205-209, doi: 10.1016/s02726386(12)80973-5.

32. Otunola GA, Oloyede OB, Oladiji AT. Effects of diet induced hypercholesterolemia on the lipid profile and some enzyme activities in female Wistar rat. Afr J Biochem Res. 2015; 4(6): 149-154.

33. Petrica L, Marius R, Schiller A, et al. Prognosis Markers Of Tubulointerstitial Injury In Primary Type I Mesangiocapillary Glomerulonephritis. FACTA UNIVERSITATIS Series: Medicine and Biology. 2001; 8(1): 19.

34. Pinheiro FV, Pimentel VC, De Bona KS, et al. Decrease of adenosine deaminase activity and increase of the lipid peroxidation after acute methotrexate treatment in young rats: protective effects of grape seed extract. Cell Biochem Funct. 2010; 28(1): 89-94, doi: 10.1002/cbf.1627, indexed in Pubmed: 20029956.

35. Preuss HG, Wallerstedt D, Talpur N, et al. Effects of niacin-bound chromium and grape seed proanthocyanidin extract on the lipid profile of hypercholesterolemic subjects: a pilot study. J Med. 2000; 31(5-6): 227-246, indexed in Pubmed: 11508317

36. Safa J, Argani H, Bastani B, et al. Protective effect of grape seed extract on gentamicin-induced acute kidney injury. Iran J Kidney Dis. 2010; 4(4): 285-291, indexed in Pubmed: 20852368.

37. Sousa E, Uchôa-Thomaz A, Carioca J, et al. Chemical composition and bioactive compounds of grape pomace (Vitis vinifera L.), Benitaka variety, grown in the semiarid region of Northeast Brazil. Food Sci Tech (Campinas). 2014; 34(1): 135-142, doi: 10.1590/s0101-20612014000100020.

38. Spiller GA, Story JA, Furumoto EJ, et al. Effect of tartaric acid and dietary fibre from sun-dried raisins on colonic function and on bile acid and volatile fatty acid excretion in healthy adults. Br J Nutr. 2003; 90(4): 803-807, indexed in Pubmed: 13129449.

39. Stemmer K, Perez-Tilve D, Ananthakrishnan G, et al. Highfat-diet-induced obesity causes an inflammatory and tumor-promoting microenvironment in the rat kidney. Dis Model Mech. 2012; 5(5): 627-635, doi: 10.1242/ dmm.009407, indexed in Pubmed: 22422828.

40. Taylor R, Hayes KE, Toth LA. Evaluation of an anesthetic regimen for retroorbital blood collection from mice. Contemp Top Lab Anim Sci. 2000; 39(2): 14-17, indexed in Pubmed: 11487233

41. Thiruchenduran M, Vijayan NA, Sawaminathan JK, et al. Protective effect of grape seed proanthocyanidins against cholesterol cholic acid diet-induced hypercholesterolemia in rats. Cardiovasc Pathol. 2011; 20(6): 361-368, doi: 10.1016/j.carpath.2010.09.002, indexed in Pubmed: 21130002

42. Wan CW, Wong CNY, Pin WK, et al. Chlorogenic acid exhibits cholesterol lowering and fatty liver attenuating properties by up-regulating the gene expression of PPAR- $\alpha$ in hypercholesterolemic rats induced with a high-cholesterol diet. Phytother Res. 2013; 27(4): 545-551, doi: 10.1002/ptr.4751, indexed in Pubmed: 22674675.

43. Zern TL, Fernandez ML. Cardioprotective effects of dietary polyphenols. J Nutr. 2005; 135(10): 2291-2294, doi: 10.1093/ jn/135.10.2291, indexed in Pubmed: 16177184.

44. Zhang Q, Raoof M, Chen Yu, et al. Circulating mitochondrial DAMPs cause inflammatory responses to injury. Nature. 2010; 464(7285): 104-107, doi: 10.1038/nature08780, indexed in Pubmed: 20203610.

45. Zoecklein B, Fugelsang K, Gump B, et al. Phenolic compounds and wine color. Production Wine Analysis. 1990: 129-168, doi: 10.1007/978-1-4615-8146-8 7.

46. Zoja C, Abbate M, Remuzzi G. Progression of renal injury toward interstitial inflammation and glomerular sclerosis is dependent on abnormal protein filtration. Nephrol Dial Transplant. 2015; 30(5): 706-712, doi: 10.1093/ndt/gfu261, indexed in Pubmed: 25087196. 